\title{
Considerations for Program Directors in the 2020-2021 Remote Resident Recruitment
}

\author{
Thomas M. Soeprono $^{1}$ (D) $\cdot$ Laurel D. Pellegrino ${ }^{1} \cdot$ Suzanne B. Murray ${ }^{1} \cdot$ Anna Ratzliff $^{1}$
}

Received: 8 June 2020 / Accepted: 29 September 2020 / Published online: 27 October 2020

(C) Academic Psychiatry 2020

The Association of American Medical Colleges (AAMC) has recommended that residency interviews be conducted remotely in light of public health risks associated with traveling during the COVID-19 pandemic [1]. Program directors have limited time to make major changes to their recruitment methods with inadequate preliminary guidelines $[2,3]$.

There will be multiple challenges involved with such a significant, rapid change. Medical students use geographic location as a major factor in their match decision $[4,5]$. Without visiting a new city, it will be harder to commit to living in a new location. It may also be more challenging to appreciate the unique strengths and weaknesses of a program without an in-person interview and tour.

Despite these challenges, remote recruitment presents opportunities similar to those that surfaced during the transition of clinical care and didactics to video platforms. Remote interviews alleviate scheduling, travel, and financial barriers associated with in-person interviews $[6,7]$. Since monetary costs disproportionately affect underrepresented minority students and students of lower socioeconomic status, reducing them has the potential to increase equity $[8,9]$. Programs will save money in the transition to remote interviews [10], which is especially relevant as programs face budget shortfalls during the COVID-19 pandemic. Programs may also benefit from having a broader pool of applicants with increased geographic diversity.

This paper provides program directors with initial ideas and considerations for remote recruitment to match interns suited to their program. The best practice guidelines from the AAMC for conducting residency interviews [11] continue to be relevant for remote interviews with some creative and logistical modifications. There have already been positive reports of

Thomas M. Soeprono

thomasms@uw.edu

1 University of Washington, Seattle, WA, USA using remote interviews effectively for recruitment to residency programs [12-16].

\section{Screening Applications}

Remote interviews are more accessible to medical students with limited time and money for traveling, which will increase the incentive to apply to more programs. However, most programs are not likely to significantly increase their interview slots due to constraints on faculty and resident time. Programs have already experienced an increased number of applicants over the last 5 years [17], and a further increase will require even more faculty time to review applications.

Applicant screening will be especially important to determine which applicants are truly interested in a program. A structured screening tool with points for various elements of the application could increase efficiency and standardization, especially if administrative staff can complete the first steps of the process [18]. Another option is to conduct brief screening interviews by phone or video with a larger number of applicants before inviting them for a full interview experience, which has been shown to be cost-effective and time-efficient [19].

Brief secondary applications can be used to identify applicants' compatibility with a program. For example, a short essay prompt could select for applicants with interests that align with a program's mission (e.g., interest in psychotherapy) or it could select for specific characterological traits that have allowed residents to be successful in the past (e.g., responsiveness to feedback). A secondary application could also filter for applicants with specific connections to a program; for example, many program directors already use geographic ties as a predictor that applicants will come to their program. A short series of checkboxes with room for expansion could confirm an applicant's interest in a specific program, geographic region, or program specialization. See Table 1 for specific examples. 
Table 1 Sample secondary application prompts

\begin{tabular}{|c|c|}
\hline Function of prompt & Sample prompt \\
\hline $\begin{array}{l}\text { Selection of applicant interests aligning with a program's } \\
\text { mission (e.g., psychotherapy) }\end{array}$ & $\begin{array}{l}\text { Tell us about a memorable time when you experienced or witnessed the healing power of } \\
\text { psychotherapy }\end{array}$ \\
\hline $\begin{array}{l}\text { Selection of residents with a specific trait (e.g., } \\
\text { responsiveness to feedback) }\end{array}$ & Tell us about a time you made a significant mistake and how you handled it \\
\hline $\begin{array}{l}\text { Checklist to filter for interest in a specific program, region, } \\
\text { and/or specialization }\end{array}$ & $\begin{array}{l}\text { [ ] Yes I am interested in applying to the University of Washington Seattle Track } \\
\text { [ ] I am interested in serving the WWAMI (Washington, Wyoming, Alaska, Montana, } \\
\text { Idaho) region for the following reason(s): } \\
\text { [ ] I am interested in learning more about Collaborative Care for the following reason(s): }\end{array}$ \\
\hline
\end{tabular}

Secondary applications may help programs reduce their applicant pool to a more manageable size. One program found that a secondary application asking for specific interest in their program caused $25 \%$ of applicants to self-select out of their pool [20]. While a secondary application presents an additional hurdle during an already time-intensive application process, there are potential advantages for both applicants and residency programs. With fewer applications to review, a program can devote more time to each application, allowing them to focus on humanistic criteria rather than numerical selection criteria (e.g., a minimum test score) to reduce the cohort size [20-22].

\section{The Interview Day}

Many interview day activities can be converted to remote settings, but there are logistical modifications to consider.

\section{Sharing Resources}

Programs that provide applicants with a welcome packet of materials about their program will now need to either mail these materials to applicants in advance of their interview day or convert them to online materials. Electronic conversion could be as simple as emailing a pdf to applicants, but programs may wish to consider richer formats such as those provided by Canvas or Medhub.

\section{Conducting Remote Interviews}

Most interviewers and applicants will be familiar with video conferencing from their experiences over the past several months. However, the anxiety of an interview raises the stakes of these interactions. We recommend orienting interviewers to best practices for remote applicant interactions. This should include practical tips, such as using a neutral background and optimal lighting, minimizing distractions, plugging portable computers into a power source, minimizing the video of oneself, and avoiding excessive movement [13]. Orientation should also include instruction to use more explicit cues to put applicants at ease because video interactions obscure subtle verbal and body language cues. Interviewers can be more expressive with their tone of voice and facial expressions. They may need to state things explicitly that would normally be interpreted through "reading the room." For example, an interviewer will need to explicitly end the interview rather than simply winding down and slowly standing up from their chair.

Technical errors can be stressful during a time-limited interview. Applicants should be reminded ahead of time to ensure a good internet connection and a quiet location for their interview. Before the interview day, applicants should be given a phone number for administrative staff to call if a link is not working or they need technical support. Interviewers should also provide a phone number to applicants to call if the video connection stops working.

All applicants should be reassured that they will not be penalized if there are technical errors interfering with their interview. This is essential to provide equal access to potentially disadvantaged groups of applicants, including those of lower socioeconomic status without the financial means to afford high-speed internet service as well as those applicants in rural and international settings where internet services may be less reliable. Programs could assess access and means prior to the interview day in order to further minimize these unintentional biases. Programs could consider providing enhanced internet access through a subsidized hotspot or they could offer phone interviews for applicants without a reliable internet connection.

\section{Types of Interviews}

One-on-one interviews can easily be converted to a remote format. Video conference interviews have not been found to result in a change in factors associated with acceptance compared with in-person interviews [16, 23], and one program even found that applicants were perceived to be more relaxed during remote interviews [16]. 
While traditional formats can be continued, some programs may use this as an opportune time to experiment with different types of interviews. There are, of course, pros and cons to each interview method. Panel interviews may be easier to coordinate in a virtual setting because faculty can easily participate from multiple locations [13]. One program found that panel interviews facilitated multiple evaluations of a candidate with a fair amount of consistency between evaluators [24]. It is easier to discretely take notes during a remote interview, so this may be a time to experiment with using behavioral and/or situational questions that are evaluated with a rubric. The AAMC best practice guidelines review the advantages and disadvantages of structured interview questions [11]. Remote interviews may allow programs to experiment with different interview lengths, such as using multiple short "miniinterviews" in which faculty evaluate applicants' response to a specific scenario [25]. Mini-interviews have been shown to work effectively in a remote setting [26].

Programs may wish to experiment with "blinding" to decrease bias. By conducting an interview over the phone, an interviewer could effectively be blinded to an applicant's appearance, complexion, and assumed socioeconomic status. This advantage must be weighed against the potential disadvantages of phone conversations, including inability to read facial expressions and other visual cues, although there is some evidence that phone interviews do not significantly change interview quality [27]. With telephone interviews, it is important to maintain engagement with strategies such as creating a professional and confident atmosphere [28], active listening, supportive vocalizations, and making validating and clarifying statements [29].

\section{Structuring the Interview Day}

Programs will need to be attentive to the time zones in which applicants are located. Programs may opt to shift the timing of their interview day or hold half-day interviews, some in the morning and some in the afternoon, so that applicants can choose the time of day that works best in their time zone. This would prevent applicants from having to interview very early or late in the day when they may not be able to perform their best and during which time they may have competing demands (e.g., applicants with young children). However, this would require increased coordination burden on administrative staff, and faculty interviewers may not have flexibility in the time that they are available.

Remote events can easily be packed too tightly together. Interactions over video conferencing can cause feelings of unease and fatigue, particularly in situations in which close reading of social cues is required [30]. It is important to schedule adequate breaks to use the restroom or simply stand up and stretch. Applicants should be given explicit permission to turn off their video cameras and microphones during breaks to ensure a restorative break. Programs may want to decrease their total number of interviews or provide longer breaks for both applicants and interviewers.

Lunch presents a challenge for online interviews. Traditionally, lunch is provided to applicants on interview days, and the lunch break provides a casual environment in which to interact with current residents. Creating a remote version of this experience is important, and while there is no substitute for eating together, there are steps programs can take to foster this more informal interaction.

Eating lunch simultaneously over video is challenging for a large group. Only one person can talk at a time, and participants may accidentally speak over each other. Small side conversations are not viable like they are during an in-person lunch. There are several ways to manage this. A resident could moderate the event, asking pertinent questions and calling on people when needed. While this is a significant departure from the informal nature of lunch on an interview day, it has the advantage of keeping the entire group together. Another approach is to use breakout sessions of smaller groupings of residents and applicants. Many video conferencing technologies facilitate this by allowing participants to interact in separate "rooms." Breakout sessions could be rotated at set intervals of time to give people a chance to meet with a broader group of applicants and residents.

\section{Supplemental Recruitment Activities}

Outside of the interview day, virtual platforms allow for a host of additional recruitment opportunities. Without the time constraint of a single interview day, activities can be offered over a longer period of time, allowing applicants to form a more nuanced assessment of a program. Some of these activities can be prepared in advance and consumed by applicants on their own time, while other events can be hosted live.

\section{Tours}

Often there are limitations to in-person tours based on time constraints and spaces where large tour groups can visit. Video recorded tours of clinical sites could cover more clinical locations through time-lapse techniques and simple editing.

For many applicants, touring the city where a program is located is just as important as viewing the hospitals, clinics, and workrooms. A recorded tour could include local restaurants, parks, and landscapes. It could even feature areas where most residents live and common activities that residents participate in.

If programs have the budget, producing professionally developed videos of the clinical sites and the program's location could help applicants feel more confident in getting to know a location without visiting in person. To save costs, program 
directors from multiple specialties could collaborate to produce a common video for all applicants. If it is not feasible to hire a professional video team, programs may opt to find residents or faculty with talents in this area who may be excited to contribute to this effort.

\section{Open Houses}

Programs could offer regularly scheduled remote "open houses" with resident and faculty volunteers. A resident or faculty moderator could take questions submitted through the chat function and pose them the participants. Some open houses could have themes, such as discussing research opportunities at a program or experiences in addiction psychiatry. Later in the season, more exclusive open houses for those who have been invited for an interview could be held with the program director and associate program directors.

Applicants could attend as many or as few as they would like, providing a low commitment, low barrier option to learn more about a program. Programs would need to clearly state that attendance is not taken and that participation does not affect the interview process.

Given the casual nature of these non-traditional recruitment settings, it is important to remind residents, faculty, and staff of match violations prior to each encounter. Having a template slide visible as participants join is one gentle way to repeat this important message.

\section{Resident Life Videos}

Residents are often the best recruiters of applicants. Willing residents could film short "day-in-the-life" videos. While they could not film patients, they could film their living space, their favorite places in their neighborhood, their commute to clinical settings, and shared work spaces. These glimpses of resident life could provide more information than a resident could relay to an applicant at an in-person dinner. Applicants try to imagine how their future self would fit into a program, and this could help applicants "feel" what this would be like.

In order to preserve residents' privacy, some consideration would have to be given to storing and sharing these videos. For example, videos could be stored on a secure site and applicants are given time-limited access codes. Or, videos could be shown on a virtual platform during the interview day.

\section{Website}

Maintaining an appealing, professional, and up-to-date website is important during the remote recruitment season. A program's website already influences applicants' first impression of a program and is one factor applicants use in deciding where to apply $[4,5]$. Some of the most important elements to include on a website are a list of current residents and faculty, campus maps, a description of the application and interview process, a list of alumnae fellowships and jobs, current or planned changes to the program or department, benefits and salary, and an academic schedule [4].

\section{Conclusion}

Despite our attempts to make the most of the change to remote recruitment, we would like to acknowledge the hardships this will cause both applicants and programs alike. There is no true substitution for meeting an individual face to face nor for exploring a new location in person. Even the best video cannot fully capture the feeling of exploring a new area for oneself. And, many of the short, informal interactions that make up an interview day will be lost in the conversion to a remote setting, which by its nature is more planned and formal [13].

We also want to acknowledge the extra burden that this places on newer residency programs. Established programs have years of experience that they are now trying to "convert" to a virtual setting, while newer programs have to transition while they are still learning how to navigate recruitment season.

As with all things new, there is increased anxiety for both applicants and programs alike. Many are feeling disappointment at the loss of their expectations and having to adjust to a new experience. As psychiatrists, we have the skills to help applicants feel comfortable during a vulnerable time.

Sharing resources across programs will be more important than ever. Participating in organizations such as the American Association of Directors of Psychiatry Residency Training (AADPRT), the Association for Academic Psychiatry (AAP), and the American Psychiatric Association (APA) can provide a venue for this through publications, work groups, and listservs. Each program will have their own strengths and weakness, and we can all stand to benefit from learning from each other's successes and failures.

\section{Compliance with Ethical Standards}

Disclosure On behalf of all authors, the corresponding author states that there is no conflict of interest.

\section{References}

1. Consensus Statement from the Association of Directors of Medical Student Education in Psychiatry (ADMSEP) and the American Association of Directors of Psychiatric Residency Training (AADPRT) on the 2020-21 Residency and Fellowship Application Cycle [Internet]. 2020 [cited 2020 Jun 3]. Available from: https://www.aadprt.org/application/files/3015/8983/6342/ admsep_aadprt_statement_5-17-20.pdf. Accessed 17 May 2020

2. Association of American Medical Colleges. Virtual Interviews: Tips for Program Directors [Internet]. 2020 [cited 2020 Jun 3]. 
Available from: https:/www.aamc.org/system/files/2020-05/ Virtual_Interview_Tips_for_Program_Directors_05142020.pdf. Accessed 17 May 2020

3. Coalition's Current Practices of Student Movement Across Institutions for the Class of 2021 Work Group. Compendium of Resources for the Implementation of Recommendations in the Final Report and Recommendations for Medical Education Institutions of LCME-Accredited, U.S. Osteopathic, and NonU.S. Medical School Applicants [Internet]. 2020 [cited 2020 Jun 5]. Available from: https://www.aamc.org/system/files/202005/covid19_Compendium_Resources_05112020.pdf. Accessed 17 May 2020

4. Deloney LA, Perrot LJ, Lensing SY, Jambhekar K. Radiology resident recruitment: a study of the impact of web-based information and interview day activities. Acad Radiol. 2014;21(7):931-7.

5. Mahler SA, Wagner M-J, Church A, Sokolosky M, Cline DM. Importance of residency program web sites to emergency medicine applicants. J Emerg Med. 2009;36(1):83-8.

6. Vadi MG, Malkin MR, Lenart J, Stier GR, Gatling JW, Applegate RL. Comparison of web-based and face-to-face interviews for application to an anesthesiology training program: a pilot study. Int $\mathbf{J}$ Med Educ. 2016;7:102-8.

7. Shah SK, Arora S, Skipper B, Kalishman S, Timm TC, Smith AY. Randomized evaluation of a web based interview process for urology resident selection. J Urol. 2012;187(4):1380-4.

8. Peek ME, Kim KE, Johnson JK, Vela MB. "URM candidates are encouraged to apply": a national study to identify effective strategies to enhance racial and ethnic faculty diversity in academic departments of medicine. Acad Med J Assoc Am Med Coll. 2013;88(3):405-12.

9. Workforce I of M (US) C on I and P-LS for I the D of the USH, Smedley BD, Butler AS, Bristow LR. Increasing Diversity in the Health Professions: A Look at Best Practices in Admissions [Internet]. In the Nation's Compelling Interest: Ensuring Diversity in the Health-Care Workforce. National Academies Press (US); 2004 [cited 2020 Jun 7]. Available from: https://www.ncbi.nlm. nih.gov/books/NBK216007/. Accessed 17 May 2020

10. Pourmand A, Lee H, Fair M, Maloney K, Caggiula A. Feasibility and usability of Tele-interview for medical residency interview. West J Emerg Med. 2018;19(1):80-6.

11. Association of American Medical Colleges. Best Practices for Conducting Residency Program Interviews [Internet]. 2016 [cited 2020 Jun 3]. Available from: https://www.aamc.org/system/files/ 2020-05/best $\% 20$ practices $\% 20$ for $\% 20$ conducting $\% 20$ residency $\%$ 20program\%20interviews.pdf. Accessed 17 May 2020

12. Healy WL, Bedair H. Videoconference interviews for an adult reconstruction fellowship: lessons learned. J Bone Joint Surg Am. 2017 Nov 1;99(21):e114.

13. Williams K, Kling JM, Labonte HR, Blair JE. Videoconference interviewing: tips for success. J Grad Med Educ. 2015;7(3):331-3.

14. Pasadhika S, Altenbernd T, Ober RR, Harvey EM, Miller JM. Residency interview video conferencing. Ophthalmology. 2012;119(2):426-426.e5.

15. Daram $\mathrm{S}, \mathrm{Wu} \mathrm{R}$, Tang $\mathrm{S}$. Interview from anywhere: feasibility and utility of web-based videoconference interviews in the gastroenterology fellowship selection process. Am J Gastroenterol. 2014;109(2):155-9.

16. Melendez MM, Dobryansky M, Alizadeh K. Live online video interviews dramatically improve the plastic surgery residency application process. Plast Reconstr Surg. 2012;130(1):240e-1e.

17. National Resident Matching Program. Results and Data: 2020 Main Residency Match [Internet]. 2020 [cited 2020 Jun 6]. Available from: https://mk0nrmp3oyqui6wqfm.kinstacdn.com/wp-content/ uploads/2020/05/MM_Results_and-Data_2020.pdf. Accessed 17 May 2020

18. Smith EM. Telephone interviewing in healthcare research: a summary of the evidence. Nurse Res. 2005;12(3):32-41.

19. Edje L, Miller C, Kiefer J, Oram D. Using Skype as an alternative for residency selection interviews. J Grad Med Educ. 2013;5(3): 503-5.

20. Puscas L, Esclamado R. Use of a secondary essay in the residency application process. JAMA Otolaryngol- Head Neck Surg. 2015;141(7):591-2.

21. Naclerio RM, Pinto JM, Baroody FM. Drowning in applications for residency training: a program's perspective and simple solutions. JAMA Otolaryngol Neck Surg. 2014;140(8):695-6.

22. Boyd CJ. Implementation of a secondary application to increase efficiency in the plastic surgery match. Ann Plast Surg. 2020;84(5):475.

23. Ballejos MP, Oglesbee S, Hettema J, Sapien R. An equivalence study of interview platform: does videoconference technology impact medical school acceptance rates of different groups? Adv Health Sci Educ. 2018 Aug 1;23(3):601-10.

24. Illahi Y, Alkhoury G, Khan Z, Barnett W, Assaly R. Panel interview for internal medicine residency selection: pros and cons. Int $\mathrm{J}$ Med Educ. 2017;8:59-60.

25. Drabble L, Trocki KF, Salcedo B, Walker PC, Korcha RA. Conducting qualitative interviews by telephone: lessons learned from a study of alcohol use among sexual minority and heterosexual women. Qual Soc Work QSW Res Pract. 2016;15(1):118-33.

26. Tiller D, O'Mara D, Rothnie I, Dunn S, Lee L, Roberts C. Internetbased multiple mini-interviews for candidate selection for graduate entry programmes. Med Educ. 2013;47(8):801-10.

27. Sturges JE, Hanrahan KJ. Comparing telephone and face-to-face qualitative interviewing: a research note. Qual Res. 2004;4(1): 107-18.

28. Villwock JA, Hamill CS, Sale KA, Sykes KJ. Beyond the USMLE: the STAR algorithm for initial residency applicant screening and interview selection. J Surg Res. 2019;235:447-52.

29. Gauge applicants' non-cognitive attributes with multiple mini interviews format. Resid Program Alert. 2019;17(1):1-6.

30. Why Zoom Is Terrible - The New York Times [Internet]. [cited $2020 \mathrm{Jul}$ 27]. Available from: https://www.nytimes.com/2020/04/ 29/sunday-review/zoom-video-conference.html. Accessed 2 Aug 2020

Publisher's Note Springer Nature remains neutral with regard to jurisdictional claims in published maps and institutional affiliations. 